\title{
[Entrevistas]
}

\section{Conversando con Alberto Ciria ${ }^{1}$ \\ Talking with Alberto Ciria \\ ALBERTO CIRIA-ALEJANDRO ROJAS}

\begin{abstract}
RESUMEN
Conversación entre Alberto Ciria, ganador del premio anual 2015 a la promoción de la filosofía y la cultura en Málaga que entrega FICUM, y Alejandro Rojas (presidente de FICUM) en torno a la pregunta ¿qué es para ti la filosofía?
\end{abstract}

PALABRAS CLAVE

FILOSOFÍA, FUNDAMENTO, LIBERTAD, CIENCIA, TIEMPO

\begin{abstract}
Discussion between Alberto Ciria (winner of the annual prize 2015 to the promotion of the philosophy and culture in Málaga; FICUM delivered) and Alejandro Rojas (President of FICUM) around the question: what is philosophy for you?

KEY WORDS

PHILOSOPHY, GROUNDS, FREEDOM, SCIENCE, TIME
\end{abstract}

Claridades. Revista de filosofía, 7 (2015), pp. 107-128

ISSN: 1889-6855 ISSN-e: 1989-3787 Dl.: PM 1131-2009

Asociación para la promoción de la Filosofía y la Cultura (FICUM)

\footnotetext{
${ }^{1}$ Esta entrevista fue publicada originariamente en el portal FILOSOFÍA NOTICIAS de FICUM el 28 de mayo de 2015.
} 
MUY CONOCIDO EN EL MUNDO ACADÉMICO POR sus magníficas traducciones sobre Fichte, Heidegger y Lauth, Alberto Ciria ha sido autor de numerosos y excelentes trabajos académicos en los que aflora la filosofía más genuina y pura junto a un profundo conocimiento del mundo de las artes poéticas: música, literatura, pintura... lo que convierte a sus trabajos en algo a lo que estamos últimamente poco acostumbrados: en ensayos de algo que está vivo y que se nos escapa, que tiene matices y mensajes ocultos. Convendría destacar también que la fuerza de sus composiciones reside en parte en haber sido concebidas como obras de paso, que no persiguen su consagración (la gloria, que diría Machado), que no quieren perdurar, sino fructificar a costa de su provisionalidad poniendo en acto algo que está siempre en marcha y que nunca pasa del todo.

Alberto Ciria rehúye la fama y su apariencia de virtud y plenitud, para hacer filosofía mundana: esa que no se aparta del mundanal ruido, que se levanta aprovechando las pausas y las barreras de la vida, sus impulsos y sus enseñanzas, sus límites y posibilidades... lejos pues de la fría academia donde el filósofo corre siempre el peligro de replegarse sobre sí mismo pagando el enorme coste de la estatificación de lo provisional. Lo provisional a veces se estatifica, y no sólo la obra sino también el filósofo. Se convierte en una estatua de sal alrededor de la cual florecen aduladores que practican el egepticismo alrededor de lo que alaban. Lejos de este peligro se sitúa Alberto. A distancia de todo. Ejerciendo su quehacer filosófico desde la extenuación y la pesadumbre. Mostrando continuamente que la filosofía no tiene que ver con famas, prestigios ni aplausos, sino con algo mucho más íntimo, sencillo y mundano. Que es una actividad que sólo puede entenderse como algo que nace en y desde el mundo, y por ello que nace de la mundanidad y de la in-mundicia.

Su relación con Málaga es muy especial. En esta Málaga sureña y provinciana siempre ha sido Alberto muy querido. En parte por pertenecer al entonces flamante Círculo de Torre del Mar; ahora tristemente vivo sólo en rescoldos. También muy querido por hacer de anfitrión a los malagueños que deseaban conocer Europa escapando del provincianismo. Si bien, últimamente es conocido muy especialmente por compartir su conocimiento, experiencia y singular personalidad y perspectiva a través de las distintas actividades que la asociación FICUM promueve en esta ciudad. Su última gran aportación al ámbito filosófico cultural malagueño han sido sus diálogos en el ágora de la filosofía que se hace en 
Málaga $^{2}$ sus columnas en nuestro portal de noticias ${ }^{3}$ donde siempre resulta un placer leerle dejarnos mover a pensamientos y perspectivas muy singulares y apasionantes.

Desde FICUM consideramos que Alberto Ciria es uno de esos filósofos que, sin aspavientos ni reivindicaciones, más hace por la promoción de la filosofía y la cultura en Málaga. Por ello, queremos reconocerle su dedicación a la promoción de la filosofía en esta ciudad con nuestro humilde "PREMIO ANUAL 2015 A LA PROMOCIÓN DE LA FILOSOFÍA EN MALAGA".

He tenido la oportunidad de entablar con él una pequeña conversación a propósito de la entrega de este premio. Para mí ha sido un placer conversar con él, y espero que disfrutéis de esta entrevista imposible, de esta conversación entre amigos, que os acercará un poco a la figura de este enorme filósofo que niega serlo porque no encaja bien con ningún cliché ni concepción de la filosofía, porque se mueve siempre en márgenes y límites, entre distintos modos de sabiduría... y he aquí que mi primera pregunta, aunque la vaya a negar o ajustar, no puede ser otra que:

\section{Alejandro Rojas: ¿qué es para ti la filosofía?}

Alberto Ciria: Querido Alejandro, me siento muy emocionado, pero tengo la impresión de que me confundes con otra persona. Lleno de esta doble sensación incrédula de honor inmerecido y de suspicacia de equivocación que no se atreve a preguntar para asegurarse por miedo a estropearlo todo, me sentiré muy dichoso de reentregar este premio -no concibo que a mí se me pueda premiar por nada- a todos los participantes de nuestro ágora, y especialmente a ti: en realidad, el premio te lo tendrías que dar a ti mismo. Dicho esto, paso a tu pregunta.

“¿Qué es para ti la filosofía?” y “¿qué es la filosofía para ti?” son dos preguntas distintas. La primera, que es la que tú me haces, con la que se pregunta por la concepción que uno tiene de la filosofía, sólo se atrevería a responderla alguien que es filósofo o que se piensa que lo es, pero como yo no pertenezco a ninguno de ambos grupos, esa pregunta la tendrá que responder otro. Como me doy cuenta de que si empezamos así no iremos a ninguna parte, voy a responder la segunda pregunta, con la que

\footnotetext{
2 https://www.facebook.com/groups/127246410717764/

3 https://sites.google.com/site/lacronicadelvisitante/filosofia-noticias
} 
se pregunta por el sentido que tiene o por la función que desempeña la filosofía en la vida de uno, y cuya diferencia con la primera implica su pleno carácter personal, subjetivo e intransferible, pero por el mismo motivo también incontestable.

Hay una manera de conocer las esencias de las cosas que es siéndolas compartidamente. Es la famosa tesis aristotélica de que, al conocer, el alma es en cierta manera todas las cosas. Esa "cierta manera" de ser las cosas es compartir su ser. Aunque esto suena por un lado muy clásico, y por otro lado muy gnoseológico y teórico, es alguien tan moderno y tan anhelante de vivir como el Fausto de Goethe quien formula esta aspiración expresando sus ansias de bañarse en la luz de la luna.

Hay una diferencia entre bañarse en la luz de la luna y bañarse $a$ la luz de la luna, pero, aparte de que Fausto menciona ambas cosas, esa diferencia no debe hacernos perder de vista que la palabra central de la frase es el verbo "bañarse".

Bañarse en la luz de la luna se hace desnudo, lo cual no es exhibicionismo sino su contrario, pues si existe en el universo un sitio sin espectadores, es justamente éste: el campo del conocimiento esencial. La ausencia de público viene ya implicada en la metáfora del baño nocturno. Esto explica por qué la filosofía es tan rara: porque casi todo lo que hacemos $-\mathrm{y}$ nosotros más que nadie-, lo hacemos para un público. Hay un público externo, y hay otro público interior que todos portamos dentro de nuestras cabezas. ¿Quién se atreve hoy a vivir sin espectadores? Filosofar es bañarse con las esencias en el río del ser. Sin público, desnudo, por la noche: aquí hay una ascesis, pero también un erotismo. (Ahora que digo esto, me doy cuenta de que muchas representaciones pictóricas de la edad de oro muestran a muchachas bañándose desnudas en un río.) Desnudarse significa aquí prescindir de esas justificaciones externas (como una subvención o un certificado) e internas, y de aparatos en los que nos gusta ampararnos cuando no resistimos la falta de confirmaciones. La metáfora del río se asocia siempre a Heráclito, pero "bañarse" es una paráfrasis plástica de ese verso de Parménides que -sin entrar ahora en traducciones- dice que ser y pensar son lo mismo o que están en lo mismo. Metafóricamente, bañarse es entrar en la esencia de las cosas compartiendo su ser gracias al conocimiento. Esto puede lograrse en extraordinarios momentos de contemplación o de teoría, pero también, simplemente, en momentos de vida pura. Pero cuando esas esencias nos cierran sus puertas -nada más recatado que el ser, y por eso los especta- 
dores lo ahuyentan y hay que salir a buscarlo por la noche-, entonces hay que llamarlas para que salgan afuera, y hay que llamarlas por su nombre propio. Esos nombres propios cada uno tiene que encontrarlos por sí mismo, de nada sirve leerlos en otros y luego andar por ahí repitiéndolos. Acertar con el nombre propio es la formalización, que no tiene por qué ser expresa. ¿Acaso no hay llamadas y encuentros mudos?

Ser compartidamente lo distinto de sí conociéndolo: eso tendría que ser también la ciencia, y en efecto la filosofía nace como física. En lugar de eso, la ciencia actual trabaja con modelos, que son sustituciones manejables de las esencias, como también percibe Fausto un poco más adelante en la misma escena nocturna al hojear el libro de Nostradamus: "iQué espectáculo! Pero, jay!, nada más que un espectáculo". Manejando modelos -y como dice el personaje de "Solaris" con una metáfora que en este contexto podemos contraponer a la del baño-, nos miramos en un espejo.

En cambio, si la poesía, y el arte en general, es el pronunciamiento de los nombres propios de las cosas para hacer salir sus esencias, o las esencias mismas que han salido afuera después de que las cosas han sido llamadas por su nombre, es algo que habrá que seguir precisando.

AR: Me parece un modo realmente hermoso de definir lo que es el quehacer filosófico decir que consiste en un baño en la luz de la luna aprovechando el apoyo de las líneas del Fausto. Hablando de lunas, desnudos y a propósito de tu referencia a la ciencia actual, recuerdo que Feyerabend protesta airadamente contra el modo en el que se expresan los expertos actuales comparando las vivas y pasionales líneas de Galileo y Kepler sobre la luna con unas frías, desapasionadas y objetivas líneas sacadas de un best-seller titulado "la respuesta sexual humana". Me parece que Galileo y Kepler podrían ser buenos ejemplos de personas bañándose en la luz de la luna, disfrutando de sus hallazgos. Podría incluso pensarse que el estilo de Galileo y Kepler se asemeja al género epistolar (que no piensan en el público académico) en la medida en que, si lo comparamos con el modo en el que hoy se habla, pareciera que ellos no piensan en el público académico, sino que relatan sus propias sensaciones, experiencias y emociones como el que le habla a un amigo o lo confiesa en un diario. Voy a recoger con tu permiso un pequeño extracto:

"Hay otra cosa que no puedo dejar de lado, ya que cuando la vi me produjo auténtica admiración. Se trata de que casi en el centro de la Luna 
hay una depresión más grande que todas las demás. He estado observando esta hondonada alrededor del primero y del último cuarto de Luna y he intentado reproducirla lo más exactamente en el segundo de los dibujos de arriba."

Dice Feyerabend después de recoger varios textos parecidos:

"He observado, he visto, estaba sorprendido, estoy asombrado, estaba encantado; ésta es la manera en que uno se dirige a un amigo"

Desde luego no se habría perdido -si hacemos caso a Feyerabendsólo un modo humano de expresarse, sino que pareciera como si se hubiera deshumanizado la ciencia, o despersonalizado... como si fuera pecaminoso -por humano y vivo- ese baño en la luz de la luna en el que pensar y ser llegan a identificarse. Sin embargo, hoy sería un "suicidio" académico hablar de otro modo... ¿cabría pensar acaso que es posible traducir aquella experiencia originaria a un lenguaje académico aceptado (que oculte que aquellas sensaciones han tenido lugar)? ¿Dirías que por evitar el "suicidio académico" el filósofo se ha suicidado como tal en la medida en que al desligarse de ese modo de la experiencia ha perdido su suelo? ¿Tenemos que elegir entre -lo diré citando tus palabras- "ser cómplices del espectáculo vacío" y la experiencia mágica de "bañarse en las esencias de las cosas"?

$A C$ : Recoges los versos del Fausto para establecer una diferencia entre la expresión personal y la expresión académica. ¿Pero acaso no es el Fausto el paradigma de obra consagrada académicamente? ¿Acaso no es su autor el paradigma de personalidad consagrada académicamente? ¿Hay estatuas pétreas más asentadas e inamovibles que las de Goethe, que de este modo alcanzó lo contrario de lo que tú llamas „suicidio académico“, y que haciendo una antítesis con ese término podríamos llamar ,inmortalidad académica“? Y eso que la escena más famosa del Fausto -por no decir que la tragedia entera- es una sátira contra los profesores universitarios... y los alumnos universitarios, con un Mefistófeles disfrazado de „magister“. Hace unos meses deambulé por un claustro universitario circundado de bustos marmóreos de unas pesadas cabezas que en su tiempo debieron pertenecer a insignes académicos que ahora han caído no sólo en el más absoluto "olvido académico“ -por seguir con nuestra terminología-, sino en el más absoluto „desinterés académico“. Eso sí que es una ironía. Como se dice en el famoso soneto número cincuenta y cinco de Shakespeare, los versos sobreviven al mármol. 
Pero la diferencia entre „expresión personal“ y „expresión académica“ se enmarca en un contexto que tiene mucho más alcance. Es el tema de los cauces pretrazados. Cada uno de nosotros nos debatimos en el dilema entre estos dos polos: ese horror a quedarnos fuera de todo cauce que nos conduce a precipitarnos a cauces hechos, frente a la necesidad de hacernos un cauce propio con el que exclusivamente se identifique cada uno; la aversión a seguir cauces masivos frente al horror a quedarse solo. Para ilustrar este dilema con un ejemplo extraído del contexto en el que tú lo piensas, sería el caso del académico que se amuralla en su especialidad reducida (una „parcelita“, como lo denominaba una entrañable amiga, miembro de nuestro foro), construyéndose unas paredes alrededor, para tener la sensación de que, al menos en ese campo (o en esa „parcelita"), es una autoridad y tiene algo que decir, y -como el oso que se orinaba en los árboles del que hablábamos recientemente en el foropercibiendo como un intruso a todo aquel que se acerca a husmear.

Es propio del hombre poder rehusar. Para otros seres su dignidad mayúscula radica en no poder rehusar, en ser uno con sus órbitas y sus cauces, hasta el punto de que el rehusamiento representaría para ellos una autonegación radical de su ser, esto es, una condenación (la desobediencia que transforma al ángel en diablo y que le hace salirse de su órbita cayendo -por otra parte, la tesis escolástica e igualmente poliana de que cada ángel agota su especie se podría formular también así: cada ángel tiene su órbita exclusiva-). Frente a eso, la dignidad suprema del hombre radica en poder rehusar y a veces en hacerlo (como una dignificación máxima del hombre se puede leer el pasaje de las tres tentaciones, que son contestadas con tres rehusamientos); en tener a disposición órbitas y cauces pero no ser uno con ellos, es decir, en poder ir a la deriva. Y yendo a la deriva poder entrar, transitoriamente o para siempre, en órbitas y cauces ajenos o sin dueño, a veces para enajenarse y a veces para recobrarse. Hay personas que, por el temor de quedarse atrás, lo dan todo por subirse a una órbita que ya está en marcha, que lleva definida y nombrada desde hace un tiempo. Otras personas lo dan todo para buscarse una órbita sin dueño y, dejándola innombrada, situarse ahí, lejos de toda definición.

Por eso, además de que no se puede plantear una alternativa excluyente entre „expresión personal“ y „expresión académica“, hay que darse cuenta de que de nada sirve la expresión sentimental más afectada ni la expresión académica más canónica si no se tiene nada esencial que decir. 
Pero si se tiene algo esencial que decir, entonces hay que hacer el esfuerzo por hallar la expresión que le haga más justicia a eso esencial que pide ser nombrado, en lugar de ir repitiendo por ahí lo que hemos oído decir a otros, con sus mismas palabras y hasta con sus mismos gestos. Con nuestro lenguaje habitual, tanto con el coloquial como con el científico, normalmente nos movemos en algo que podríamos llamar ,semicomprensibilidades", es decir, cosas comprendidas a medias. Y este sentido de una „expresión que hace justicia“ se puede aplicar tanto a la expresión poética como a la fórmula científica.

Con esto paso a retomar el caso de Galileo y Kepler que tú mencionas. No es sólo que los textos científicos de estos genios asuman a veces la forma de una correspondencia o diario personal, sino que a veces asumen la forma de textos no ya filosóficos, sino poéticos, y aquí se podría mencionar a Newton. Como sabes, el newton es la unidad de fuerza, cuya fórmula es: , $\mathrm{f}=\mathrm{m} \mathrm{x} \mathrm{a}$ “. Esta fórmula no es un conocimiento, sino la expresión científica de un conocimiento (si recordamos el famoso cuadro de Magritte, entre la fórmula y el conocimiento hay la misma diferencia que entre el dibujo de la pipa y la pipa). Ese mismo conocimiento yo lo puedo expresar filosófica y poéticamente así:

Porque todo es relevante para todo, todo lo que es, por el mero hecho de ser, tiende a juntarse, y esa tendencia es tanto más vehemente cuanto más próxima está de consumarse.

O así:

Todo lo que es, por el mero becho de ser, está en un declive constante con la vehemencia creciente de su atracción mutua en la que se evidencia su reciproca relevancia. A esa relación la llamamos fuerza.

El verdadero científico no es el que se sabe de memoria y aplica correctamente la fórmula „f $\mathrm{f}=\mathrm{m} \times \mathrm{a}$ a“, sino el que, habiendo llegado a entender el sentido del conocimiento que esa fórmula expresa, es capaz de reformularlo -y siente la necesidad de hacerlo- con sus palabras propias.

Con tu cita de Kepler y Galileo tú retomabas el tema de la luna, que yo había mencionado con la metáfora que emplea Fausto. ¿Quiénes son los lunáticos? Svidrigailov, el personaje de Crimen y castigo, se representa la eternidad como estar encerrado en un cuarto de baño, y yo me represento el estar muerto como deambular por la cara oculta de la luna. Qué sentido tiene eso, nos lo dice la película de Fritz Lang „La mujer en la luna“, que precisamente comienza con el caso del astrónomo que, por dar forma científica a sus visiones -que, por cierto, al final se acaban 
constatando empíricamente-, es excluido de la comunidad científica y condenado a la marginalidad y el ostracismo académicos y al trastorno psíquico. La comunidad científica es representada en la película por una asamblea de vejestorios decrépitos, engreídos y gruñones.

La película narra el viaje a la luna de un grupo de científicos, las motivaciones previas que les llevan a emprender ese viaje -que, quizá exceptuando al viejo trastornado, para ninguno de los personajes son exclusivamente científicas, sino que van desde la fidelidad hasta la ambición pasando por el despecho y el orgullo- y lo que sucede una vez que alunizan. Ahora es oportuno comentar la escena del despegue. Mientras "las miradas y los oídos de todo el mundo están puestos en ellos”-como dice literalmente un rótulo de la película muda-, los científicosastronautas se suben muy envalentonados al cohete. A diferencia del resto de la película -que dura tres horas-, que está rodada desde la perspectiva de los personajes protagonistas (si un personaje está sentado, su interlocutor de pie es filmado desde abajo), la escena del despegue está rodada desde la perspectiva del público que asiste al acontecimiento en vivo o que lo sigue por la radio. Fritz Lang prolonga deliberadamente esta escena, que apenas tiene función narrativa, precisamente para dejar bien claro que, lo que propulsa el cohete, tanto como el carburante y como el deseo de saber y demás motivaciones, son las oleadas de viento que levanta el aplauso del mundo. "¿Bajarme del cohete ahora que todo el mundo me está mirando?" Pero cuando los científicos han alunizado en la cara oculta de la luna y han perdido todo contacto con la tierra, sus máscaras se les retiran y ellos se quedan expuestos, ante los demás y ante sí mismos, a su terrible situación de desnudez espiritual, simbolizada por el desierto lunar, inhóspito por vacío. Entonces quedan al descubierto las más profundas motivaciones de cada uno, esos deseos que por ser tan íntimos nos son desconocidos incluso para nosotros mismos -éste es el tema de Edipo, pero también el de la película Stalker de Tarkovski-, y entonces queda de manifiesto, como ante un juzgado inapelable, quién no resiste su propia desnudez, quién sí la resiste, y quién le da amparo. Eso es "la mujer en la luna": el amparo de la terrible desnudez espiritual ante sí mismo, metafóricamente la tienda de campaña -que en la escena final la mujer tiene a sus espaldas- en el desierto lunar.

AR: Un maestro en buscar nombres propios, para muchos un ejemplo de lunático, y desde luego alguien que supo ir y venir de una órbita a 
otra hasta encontrar una innombrada y sin dueño en la que alunizar, fue Heidegger. Recuerdo con mucho cariño (porque fue mi primer contacto serio con Heidegger en un seminario que organizamos al margen de las clases cuando andaba por segundo de carrera) la impresión que me causó por primera vez la lectura que hace Heidegger de Kant, concretamente cuando llama la atención de cómo la filosofía de Kant no es en absoluto un llamamiento a contener a la razón dentro de los límites del entendimiento, sino - en su lugar, y frente a las lecturas positivistas- una fundamentación de la filosofía en la medida en que pone de manifiesto que la filosofía tiene un fundamento en la naturaleza humana (algo muy ilustrado) en función de lo cual no tiene sentido el viejo dogmatismo (ni el nuevo objetivismo), sino sólo la comprensión de que se trata de un ejercicio eminentemente práctico donde lo que está en juego es la propia libertad de la razón para ir más allá -fundamentándolo en un naturalismo muy en la línea de Hume -de sus limitaciones. Este ir más allá sería lo que hace de la filosofía y del saber algo tan humano y libre, que da razón de la torpeza del dogmatismo al tiempo que de la pluralidad de razones.

No me he desviado, o si acaso no demasiado: a donde quiero ir a parar es a la siguiente pregunta: ¿crees que hoy, con el auge de la tecnología (y de esa racionalidad no meditativa que Heidegger denominaba calculadora), se tiende a deshumanizar la filosofía y la ciencia? ¿Que en lugar de aceptar que toda ciencia es un ejercicio humano, demasiado humano (basta recordar la cita de Galileo), se ha acabado por consolidar el viejo dogmatismo con su nueva máscara de "experto"; y su supuesta autoridad para decidir lo bueno de lo malo, lo racional de lunático, lo verdadero y lo falso... expertos que, sin embargo, se mueven entre -te vuelvo a citar"semicomprensibilidades" incapaces de alcanzar en la mayoría de los casos el conocimiento que hay detrás de la fórmula; considerando indecoroso e inoportuno el baño en las esencias?

Recuerdo, por poner un ejemplo de la situación actual de la sociedad, que una amiga nos contaba que había ido al pediatra a que le dijera cuántos gramos de pollo tiene que comer su bebé a la semana, y que el pediatra -como experto (aquí utilizo este término en el sentido crítico en el que lo utilizaba Feyerabend)- le había dicho una cantidad concreta, obligando a la madre a realizar labores de cuasi-alquimista. Pregunta, respuesta y la vida resultante son a mi juicio máximamente inhumanas por calculadoras, dogmáticas y poco flexibles. La pobre mujer obedecía al experto, que era una autoridad y la ejercía. Hay expertos que se ponen su

Claridades. Revista de filosofía 7 (2015) 
máscara, la que le da una bata, un sillón, un despacho... y pontifican más de lo que saben (simulando precisión) por miedo quizás a que se descubra su disfraz de experto (o exigidos por una sociedad acostumbrada a acudir a expertos) iniciando un juego en el que se oculta lo humano de todo saber, la libertad y pluralidad que hay detrás de todo juicio racional e incluso la mundanidad (por cerrar la intervención volviendo a aludir a Heidegger) que hay detrás de toda afirmación. Si bien otros, que más que expertos son maestros de aquellos, no necesitan máscaras ni disfraz, ni reconocimientos, y suponen una vía de salvación para todos.

$A C$ : En uno de sus epigramas humorísticos, Erich Kästner viene a decir que el mayor descubrimiento de la investigación científica en sus diversos campos ha sido la averiguación de que el camino más corto entre dos puntos es dando un rodeo. Como toda expresión humorística, este epigrama tiene varios sentidos. Según uno de ellos, aquí se está definiendo la investigación -pero no cualquier forma de investigación, sino concretamente la investigación con medios técnicos (a diferencia por ejemplo de discurrir sobre un tema pensando), a los que se alude en el epigrama- como una mediación necesaria: el rodeo es una metáfora de la mediación, y el rodeo como camino más corto es una metáfora de que la mediación es necesaria no por sí misma ni esencialmente, sino porque no deja alternativas mejores (el camino más corto es una metáfora del mal menor). ¿Para qué es necesaria la técnica, y por qué es necesaria como un mal menor o como alternativa menos indeseable (apréciese la lítotes)? La técnica es necesaria como mal menor porque tiene que liberarnos de dependencias peores. Por ejemplo, la luz eléctrica. Un compañero rumano me hablaba ayer sobre cómo era la vida doméstica bajo el régimen de Ceausescu: el gobierno comunista rumano restringía el suministro eléctrico a dos horas diarias. Ahora imaginémonos a una familia rumana con hijos habitando una vivienda asignada estatalmente de cuarenta metros cuadrados y dos habitaciones, alumbrándose casi todo el tiempo con velas o viviendo directamente a oscuras, y así durante veinticinco años. La luz eléctrica nos libera de depender de la luz solar: nos hace independientes del sol para desenvolvernos. El primer problema es que, liberándonos del sol, la luz eléctrica nos vuelve dependientes del suministro: si nos cortan la luz nos quedamos bloqueados. ¿Qué nos sucedería a nosotros si de pronto se nos estropea el ordenador? No es ya que no podríamos escribir, sino que no podríamos pensar: demoraríamos el seguir 
pensando hasta el momento en que el ordenador estuviera arreglado. Y ahora reparemos en que Beethoven escribió sus inmortales sinfonías a la luz de una vela. Beethoven hizo más con una vela que todos nosotros juntos con nuestros ordenadores. ¿Cuántos dientes le quedaban en la boca a Dante cuando escribió „La divina comedia“? Copérnico estudiaba los movimientos astrales distribuyendo platos llenos de agua en la cocina de su casa y observando las evoluciones de los reflejos de la luz en las paredes. ¿Cuántos aumentos y qué definición tenía el telescopio con el que Galileo descubrió la traslación terrestre? Alguien me dijo que cualquier ordenador portátil actual tiene más capacidad de memoria que las computadoras que empleó la NASA para la misión del Apolo 11. ¿Y los egipcios y los griegos, cómo demonios desarrollaron sus astronomías y sus calendarios? ¿Cómo lo hacían sin suministro eléctrico? Éste es el primer motivo por el que la técnica es un mal menor: liberándonos de dependencias mayores, nos vuelve dependientes de ella misma. Pero como de ordinario hay suministro eléctrico constante, a diferencia de lo que nos sucedía antes con el sol, que inapelablemente se esconde todas las noches, ahora acabamos perdiendo la conciencia de nuestra situación de dependencia de la luz eléctrica, y -ya generalizando- de cuán grande es nuestra menesterosidad y nuestra desnudez. Dostoievski decía que el hombre es el animal desagradecido: como todo nos lo encontramos dado, nos parece que no debemos nada a nadie. Un efecto secundario del progreso es que esta "inconsciencia de nuestra deuda" se acrecienta de generación en generación. Si no tuviéramos suministro eléctrico -por seguir con nuestro ejemplo-, todas las tardes pensaríamos en el sol y recordaríamos lo mucho que le debemos. Desde que tenemos suministro, no sólo no nos acordamos de lo que debemos al sol, sino que tampoco nos acordamos de lo que debemos a la electricidad, y así es como con el progreso técnico, que sin discusión es por sí mismo ventajoso, en lugar de entender mejor nuestra indigencia nos dejamos sumir en una engañosa sensación de poderío y dominio. Pero el hombre es más infinito gracias a su indigencia que gracias a su capacidad, por no decir ya que gracias a sus rendimientos y sus logros. "Daría todo lo que sé por la mitad de lo que ignoro": cuánta sabiduría se encierra en esta frase de Descartes, a pesar de que si la tomamos literalmente $-\mathrm{y}$ no según su intención- es engañosa, porque en ese intercambio que en términos económicos resulta ventajoso yo me pierdo a mí mismo -como si la frase fuera una versión gnoseológica de la tercera tentación-.) Un espíritu ca-

Claridades. Revista de filosofía 7 (2015) 
paz de sacar un infinito de una insignificante mota de polvo humano fue por ejemplo Kafka, de quien hemos hablado recientemente en nuestro foro. Asómate a la ventana y contempla el increíble espectáculo de la infinita miseria humana (que aparte de la pobreza también incluye el patetismo, el ridículo, la estupidez y la vanidad): pues tan inmensa como la miseria del hombre, así de inmenso es también su espíritu. Aplicando un símil futbolístico, que dedico a nuestro entrañable amigo madridista Juan García: hace falta tener un equipo muy grande para hacer un ridículo tan espantoso. De Kant y de Einstein son muy famosas sus respectivas frases sobre el infinito moral y sobre la infinita estupidez humana, pero lo que a cada uno de ellos le faltó por decir es que ambos infinitos van juntos, que cada uno se debe al otro. En su infinita indigencia destella la grandeza del hombre, y desde su tan honda caída nos grita su dignidad.

Pero hay un segundo motivo: liberándonos de necesidades vitales, la técnica nos sobrecarga de necesidades estúpidas, de modo que, habiéndonos liberado inicialmente, al final nos acaba volviendo a esclavizar. En este sentido decía Tarkovski que, si todo lo innecesario es pecado, entonces toda nuestra civilización está construida sobre el pecado. Liberando inicialmente nuestra inteligencia de urgencias vitales para dejarla más disponible, al final la técnica nos acaba idiotizando. Cuando por las mañanas viajo en metro al trabajo, observo a diario el espectáculo humano de todos los viajeros escribiendo en sus teléfonos móviles, con dos pulgares agilísimos como apéndices de insectos cefalópodos, con el frenesís de los posesos, los mensajes más estúpidos que concebirse pueda, y eso varias horas cada día. Con otros ejemplos, todo esto ya lo decía Rousseau hace doscientos años, de una manera más tremendista y menos cómica que Erich Kästner.

Pero la metáfora del rodeo que Kästner emplea en su epigrama tiene un segundo sentido: la investigación científica con medios técnicos acaba siendo un lazo, es decir, se acaba haciendo autorreferente. Esta dinámica hacia la autorreferencia no es exclusiva de la ciencia, sino que es propia de toda institución humana, según el famoso diagnóstico de Weber. Y haciéndose autorreferente, acaba perdiendo de vista el mundo vital del cual surgió y al cual inicialmente debía regresar. Y aquí es donde encaja tu anécdota del médico con la bata blanca y el fonendoscopio colgando, prescribiendo a la madre atónita, con la gravedad del facultativo colegiado, los cuarenta y siete gramos diarios de pollo. Hace unos meses tuvimos en nuestro foro la discusión sobre el método "Estivill" para que los 
bebés aprendan a dormir de un tirón, "que da resultado positivo en el noventa y cinco por ciento de los casos", que consiste en no acudir a intervalos progresivamente mayores cuando el bebé se despierta llorando por la noche. Llamar a eso el método "Estivill" es como si yo digo que durante los últimos treinta años he estado desarrollando el método "Albértovich Ciriovski" para entrar en una casa cuando no se tienen llaves, que consiste en llamar al timbre, con resultado positivo en el noventa y nueve por ciento de los casos si se cumple la condición previa de que dentro hay alguien. Este tipo de cosas las parodiaba mucho Woody Allen en algunos de sus artículos publicados en los años setenta en la prestigiosa revista científica Playboy, cuyo "índice de impacto" ya lo desearían para sí muchos científicos impenitentes. Con lo del método "Estivill", al final resultó que tanto metodismo y tanto cientificismo no era más que un pretexto para no confesar que el verdadero objetivo del experimento no es que el niño duerma de un tirón toda la noche, sino que YO duerma de un tirón toda la noche, y que el crío insomne puede berrear todo lo que quiera con tal de que a mí no me despierte.

Estos ejemplos del "médico recetapollos" y de "Estivill el metodista" enlazan otros dos temas: primero, el predicamento social de la ciencia y de los científicos, que desde el siglo XVII se ha mantenido más o menos intacto pero que no siempre ha sido exclusivo, como por ejemplo ahora; y luego, la necesidad humana de dárselas de algo, en este caso de importante, pero en otros casos de gracioso, de enterado, de concienciado, de comprometido, etc. ¿De dónde le viene al hombre la necesidad de dárselas de algo? ¿De una necesidad de ser aceptado? ¿ O simplemente de una necesidad de ser? Como quiera que sea, todo esto es mejor tomárselo a risa, como hacen Erich Kästner o Woody Allen, que tomárselo a la tremenda, como hace Rousseau.

A partir del epigrama de Kästner hemos estado hablando de la técnica como mediación, asociando la reflexión sobre la técnica a la reflexión sobre los medios. Pero hay otro pensamiento sobre los medios que nada tiene que ver con la técnica y que invita realmente, y más que ninguna otra cosa, a un baño en la luz de la luna. Últimamente he estado leyendo literatura de posguerra, un fase literaria que podría llamarse "literatura del vacío", en la que hombres sin medios escriben acerca de hombres sin medios, ni materiales ni espirituales. Son textos breves, que se leen en pocos minutos y que describen escenas sincrónicas, que también duran pocos minutos, ubicadas en ninguna parte, en paisajes desolados y abs-

Claridades. Revista de filosofía 7 (2015) 
tractos: en una vía del tren en mitad de la noche, en un paisaje sepultado bajo una capa de nieve que no permite discernir objetos ni ruidos y donde los personajes acaban enloqueciendo al poco tiempo, en el reducido espacio de un lecho o en una zanja cavada en la tierra. Escenas estancadas en un presente permanente, desconectado de un pasado destruido y de un futuro improyectable. ¿Por qué es tan importante que estos textos sean breves y que las acciones que ellos describen sean sincrónicas de la lectura? Porque en ellos se trata de la condición humana cuando para el hombre el tiempo, que ya no es dilación sino estancamiento -el tiempo como punto-, ha perdido su sentido. Quizá porque tenemos una mente muy kantiana tendemos a concebir el tiempo como una condición. Pero tanto como una condición, el tiempo es, además, un medio. Por ejemplo, el tiempo sirve para olvidar o para seguir adelante. ¿Qué le sucede al hombre cuando el tiempo es una herramienta que se ha vuelto inservible, o como diríamos hoy, una herramienta sin aplicaciones? ¿Cómo se siente el hombre cuando el tiempo ha dejado de combarse y de ser ese "rubio mastín que duerme a las puertas de Dios" -como lo describió metafóricamente Dámaso Alonso-, y ha pasado a ser un punto o -como en la instalación de Joseph Beuys- un apero de campo apoyado en la pared de un cuarto de hormigón? Al tiempo como condición le resultan irrelevantes la penuria o la bonanza humanas, pero el tiempo como medio se resiente de la situación del hombre. A veces hay que olvidar para seguir adelante (esto es, por cierto, una versión de la tercera ley de Newton: para avanzar en una dirección hay que arrojar o soltar lastre en la dirección contraria), pero si no hay un delante, entonces olvidar tampoco sirve de nada, y el tiempo mismo pasa a ser una incongruencia. En la película Cielo sobre Berlín la trapecista se pregunta: "Dicen que el tiempo cura las enfermedades, ¿pero qué sucede cuando el tiempo mismo es la enfermedad?” ¿Y qué sucede cuando el tiempo es ya no una enfermedad, a la que aún podemos dar sentido, sino un absurdo, una dimensión descontextualizada en nuestra existencia?

$¿$ ¿Hay algo que alcance a entender el hombre en medio de la carencia absoluta de medios -también de los espirituales- y gracias a esa carencia? $\mathrm{Y}$ si en esa carencia alcanza a entender algo, ¿le compensa lo suficiente de modo que pueda llegar a sentirse albergado en esa carencia, como nos pueden ilustrar las imágenes de un moribundo recostado en postura embrionaria, de un ser en vela reconciliado con el insomnio o de un enamorado del desierto (ya sea nevado, arenoso o lunar)? En momentos así, 
¿hay alguien que se ocupe de nosotros? ¿Existe "la mujer en la luna"? Con estas reflexiones sobre el tiempo como medio, tanto si es servible (por ejemplo en la experiencia de la gracia) como si es inservible, reflexiones que son más amplias y básicas que "la pregunta por la técnica", reenlazamos con la imagen inicial del baño desnudo en la luz lunar.

AR: Tu reflexión sobre la técnica me ha parecido ciertamente magistral. He quedado admirado de cómo has sabido condensar tanto en tan poco, y de cómo has sabido decirlo de un modo tan ameno. Menos claro me ha resultado sin embargo tus reflexiones finales sobre el "medio" en el que ha desembocado tu reflexión sobre la técnica. Por ello, me gustaría centrar mi siguiente pregunta en esta parte.

Para los clásicos no había duda de que el tiempo del saber era el ocioso. Ocio se dice en griego Sjolé, que dará lugar posteriormente a la schola y de ahí a nuestra española escuela. El ocio, que es el tiempo que no se dedica a resolver necesidades vitales o primarias, es por ello mismo el tiempo del hombre libre, del que en rigor "tenía" tiempo para perseguir la sabiduría. Pero al escucharte -si te he entendido bien- me daba la impresión de que ponías el acento en que habría que repensar esta noción de tiempo para repensarlo como el "medio" en el cual nos hacemos cargo de nosotros mismos y de nuestra situación en el mundo, volviéndosenos accesible el mundo a nuestro entorno. De este modo quizás evitaríamos una descontextualización de la existencia, ya que desde la concepción del tiempo como medio el baño a la luz de la luna con el que metafóricamente te referías al quehacer filosófico sería posible como una práctica vital, mundana, en camino, contextualizada... cierto tipo de existencia, un modo particular de ser en el mundo. $\mathrm{Y}$ en este sentido intento sólo comprobar que te voy siguiendo, y por ello te ruego que me rectifiques si no es así- la técnica, que nos libera de los quehaceres vitales, que nos saca del tiempo, que nos promete esa liberación clásica, nos amenaza con vaciarnos el tiempo, con impedir esa particular forma de existencia mundana. Lo cual no significa que debamos ir contra ella (se ha malentendido mucho también a Heidegger con quien continuamente te "codeas" en este punto -especialmente por parte de los filósofos de la ciencia-), sino en reconocer que "donde está el peligro está lo salvador", que lo peligroso no es otra cosa que eso mismo que nos salva. Del mismo modo que el fuego, el más peligroso de los elementos, nos salva de la vida animal y hace posible una vida humana, la técnica -que en sí misma 
puede que no sea otra cosa que la dominación del fuego- tiene la misma tarea: hacer posible una vida humana, lo que no debe pasar necesariamente por liberalizarnos de los quehaceres vitales, sino por hacer posible que éstos sean mucho más amplios que aquellos destinados a la mera subsistencia; posibilitar una existencia serena (que no ande calculando cómo llegar a fin de mes, ni cómo sacar más productividad al tiempo) y meditativa que dote de sentido filosófico todo el sinfín de quehaceres vitales.

$A C$ : La palabra "medio" tiene dos sentidos: medio como "elemento" -para el pez su medio es el agua, y para el vivo su medio es la vida- y medio como "mediación" -por ejemplo una herramienta o una intercesión-. Ambos sentidos están vinculados porque el elemento en el que un ser está inmerso es lo que media, lo que "intercede" entre él y lo que le rodea, quizá también lo que media entre él y sí mismo, y por tanto la mediación que tiene recorrer para salvar esa distancia. Pero aunque estén vinculados siguen siendo dos sentidos. El hombre no puede salirse del tiempo como su elemento -igual que el astronauta se sale de la atmósfera o el buzo se sale del agua- si no es en el momento de su muerte. Pero sin salirse del tiempo, puede entrar en una situación temporal -y en el caso de la posguerra, incluso histórica- en la que, aunque no carece del tiempo como mediación, lo percibe como una mediación inservible, como una herramienta que está de más igual que un rastrillo en un búnker. ¿Cuándo toda mediación está de más? Cuando no hay nada con lo cual mediar. ¿Y cuándo no hay nada con lo cual mediar? O bien cuando no hay nada en absoluto o nada que merezca ya ser mediado (por ejemplo en el desierto, en la luna, en una zanja, en el lecho mortuorio o en el insomnio tomándolos en sentido literal), o bien cuando habiendo mucho con lo cual mediar, la mediación misma se percibe como prescindible por insuficiente, y esto es lo que podría darse, por ejemplo, en una situación que podríamos denominar de "avenimiento universal" (como podemos representárnosla con el desierto, con la luna, con la zanja, con el lecho mortuorio o con el insomnio tomándolos en sentido metafórico). A diferencia del ocio, éstas no son situaciones que uno se proporciona ¿quién se podría proporcionar situaciones así?-, sino que sobre todo son situaciones que a uno le sobrecogen o en las que uno cae. Aunque comparten con el ocio clásico y con nuestro ocio el desentendimiento de las preocupaciones diarias por la subsistencia, son posibles en unas condi- 
ciones de precariedad extrema a las que nosotros difícilmente daríamos el nombre de ocio en ningún sentido. Es lo que representa el personaje del conde moribundo en Guerra y paz de Tolstoi: un alivio inconcebible y visionario tras un sufrimiento máximo, estar en paz con todo en medio de la extenuación más extrema. Wittgenstein describe algo así -aunque con una ambigüedad que se presta al malentendido- como la sensación de que "todo está bien como está", y Dostoievski lo expresa con mucha mayor precisión en su descripción del "aura" que precede al ataque epiléptico. Esto es un potenciamiento de la "teoría" en su sentido griego. Pero no es una definición de la filosofía. Es más y es menos. Es menos que la filosofía porque no es una comprensión. Es más porque es un asentimiento, e incluso una "bendición" si tomamos la palabra en su sentido etimológico. No es una respuesta a la pregunta filosófica "¿por qué hay ser y no más bien nada?”, sino a la pregunta no filosófica "¿merece la pena que haya ser y no más bien nada?”. Como para el campo de visión de esta pregunta desaparecen los fundamentos y las causas (ya hemos dicho que el tiempo como mediación se ha vuelto inservible), ni la pregunta es por el porqué ni la respuesta es una explicación que propicie una comprensión.

La pregunta filosófica es la pregunta por el fundamento. Pero si imitando el modo de preguntar analítico, o mejor dicho, si imitando a quienes imitan el modo de preguntar analítico formulamos la pregunta "¿acerca de qué estamos preguntando cuando preguntamos por el fundamento?", respondiendo con sinceridad tendremos que decirnos que, cuando preguntamos por el fundamento, más que conocer el fundamento, lo que queremos es comprender mejor lo fundamentado; que al preguntar por las causas, más que enterarnos de ellas, lo que queremos es entender mejor los efectos, igual que para comprender mejor las palabras estudiamos sus etimologías.

A diferencia de la pregunta filosófica por el fundamento, la pregunta por si merece la pena no se responde con una explicación, sino sólo con un "sí" o con un "no". Pero para responder a esta pregunta primero hay que plantearla. Se la puede responder sin habérsela planteado -por ejemplo cuando uno repite la respuesta que han dado otros, emulando sus gestos, es decir, gesticulando-, pero entonces es una respuesta prematura y sin peso: es taparse los ojos con una respuesta ya hecha para no ver todo el alcance de una pregunta que sigue sin haberse planteado. Mien- 
tras no concibamos todo el alcance de la pregunta, no estaremos en condiciones no ya de responderla, sino ni siquiera de formularla.

Esto no es una definición de la filosofía. Tampoco es algo que les pase a todos, o al menos no siempre, aunque quizá sí en algún momento, como en las situaciones metafóricas que hemos mencionado. Quizá no sea lo máximo que el hombre es capaz de hacer en absoluto, pero sí lo máximo que es capaz de hacer en ciertos momentos. Desde luego, no es propio de espíritus laboriosos e infatigables, como el de un Hegel o, en otro sentido, el de un Rilke. Más bien es propio de espíritus extenuados y apesadumbrados: lo último y supremo que se puede hacer cuando ya no se puede hacer nada. O glosando la descripción que hace Dostoievski del "aura" epiléptica: lo que todavía se puede hacer siempre una vez que ya se ha hecho todo (Dostoievski describe la situación de Dios en la mañana del séptimo día, cuando ya ha terminado de hacer la creación pero todavía tiene todo un largo día por delante, ya sin nada que hacer -aquí se aprecia muy bien qué significa disponer del tiempo como una mediación inservible-, y entonces se dedica a decir que todo está bien, es decir, a "bendecir").

AR: ¿Podrías aclarar, ya para terminar, el significado de esta última frase: que la filosofía es lo máximo que puede hacer el hombre, extenuado y apesadumbrado, cuando ya no se puede hacer más porque se ha hecho todo?

$A C$ : Con esta última referencia a Dostoievski, y después de que ya al comienzo hablamos de la relación entre filosofía y ciencia, podemos introducir ahora la cuestión de la relación entre filosofía y arte, que es un buen tema para terminar.

Hemos hablado del alivio, y recordamos la Consolación por la filosofía de Boecio, una de las fuentes que inspiran al personaje de La conjura de los necios, una novela que en mi época era lectura de moda entre los estudiantes (de las universidades públicas, se entiende). Recientemente asistí a una representación de Medea, de Eurípides. En una escena del inicio (no es casual que sea del inicio, ya que conforme avanzaba la representación yo cada vez podía concentrarme menos) se pronuncia esta frase: "El canto ha hecho mayor la alegría de vivir, pero nadie ha logrado acabar con el terrible sufrimiento de los hombres empleando el arte musical". Después de que en occidente llevamos tantos siglos discutiendo tan aca- 
loradamente sobre la función del arte, resulta que esta frase ya estaba pronunciada desde hacía veinticuatro siglos. ¿Se puede decir algo más sensato acerca del arte? Eurípides viene a decir esto: el arte puede ser un consuelo, pero nunca es un remedio. Jacinto Choza nos explicaba que el arte puede proporcionarnos una salvación simbólica o intencional, pero no una salvación real. También en este sentido Walter Benjamin definió el arte como una "satisfacción virtual". Sin embargo, aunque entendemos lo que Benjamin quiere decir, la formulación es imprecisa, porque las satisfacciones que el arte proporciona pueden ser muy reales. Más bien se podría decir que el arte proporciona satisfacciones reales a necesidades reales suscitadas por situaciones virtuales, es decir, representadas (en si las necesidades son reales o figuradas se decide si el arte lo es de verdad o si se queda en sofisticación).

O tal vez, antes que responder si las satisfacciones que el arte proporciona son reales o virtuales, habría que preguntar cuáles son las satisfacciones que el arte proporciona y cuáles son las necesidades. Si se supone que el arte debe proporcionar una especie de salvación o de redención (del mal, del sufrimiento, de la muerte), entonces, en efecto, sólo puede ser simbólica, intencional o virtual. ¿Pero y si la función del arte, más que proporcionar remedios, es hacernos ver las dimensiones de las necesidades? ¿Si la función del arte no es "acabar con el terrible sufrimiento de los hombres", citando de nuevo a Eurípides, sino ponernos en condiciones de llegar hasta su fondo?

¿Y la filosofía? ¿Comprender los dolores ayuda a asumirlos? Asumir los dolores no es sobreponerse a ellos de modo que dejen de doler, sino precisamente sufrirlos hasta el fondo para hacerlos parte de uno mismo. Eso es comprender los dolores: no sobrepasarlos, sino hacerse a ellos. La pregunta es entonces si para eso se necesita la filosofía. La filosofía nos hace pensar, pero el arte nos hace ver. ¿No es el propio teatro trágico de Eurípides el ejemplo más claro de cómo el arte puede sondear las dimensiones del dolor más tremendo y más absurdo, y ahondar en sus causas para, precisamente comprendiéndolas a ellas, precisamente haciéndonos ver el dolor desde sus causas, mostrarnos todo lo que tiene de inconcebible y absurdo? Aunque se suele decir que Eurípides es el más humanista y teórico de los dramaturgos trágicos griegos, lo que hemos expuesto se puede aplicar al menos en la misma medida a Sófocles. Entonces resulta que el arte no es ni consuelo ni remedio, no es salvación ni intencional ni real, no es satisfacción ni virtual ni real, sino un procedimiento 
"artificial", al menos tan eficaz como la filosofía, para, abriéndonos los ojos y ampliándonos el alma a fuerza de desgarrarla, ponernos en condiciones de llegar hasta el fondo de lo más tremendo e inconcebible.

Conocemos el pronunciamiento de Adorno de que "hacer poesía después de Auschwitz es una barbarie". La frase le quedó muy redonda, ¿pero que hay de cierto en ella? Con mayor motivo podría haber dicho que tomarse un helado o ver un partido de fútbol después de Auschwitz son actos de barbarie, porque lo frívolo de esos deleites o ansiedades representa un escarnio para las víctimas del holocausto. Frente a Adorno el intelectual, tenemos a nuestro grandísimo Pablo Casals, una de las mayores personalidades del siglo XX, preguntándose si es moral interpretar a Bach y a Beethoven -es decir, a los alemanes- durante las dos guerras mundiales que él padeció, y respondiéndose que es precisamente en aquellas épocas en las que triunfa el mal cuando se vuelve más necesario que nunca cuidar de aquello que ennoblece al hombre. El arte tiene que ver con la barbarie, como bien intuye Adorno y como paradigmáticamente realiza Eurípides, pero no porque el arte la sea, sino porque, abriéndonos los ojos y el alma para lo más inconcebible, si hace falta a base de espanto eleva nuestra dignidad a la horrible altura de lo más adverso a ella.

Alguna vez leemos en los periódicos la noticia de una mujer que ha matado a un hijo suyo. Noticias así nos consternan y suscitan en nosotros condolencia. En casos tales, los periódicos (en representación nuestra) consultan a psiquiatras y a juristas, que entonces vienen debatiendo sobre si la madre padecía depresiones o esquizofrenia, sobre si los medicamentos habían sido los apropiados, o sobre si la seguridad de terceros debe prevalecer sobre el secreto profesional y el derecho a la intimidad. Esos debates médicos y jurídicos no nos curan de la consternación, pero nos tranquilizan haciéndonos creer que esas situaciones pueden ser tratadas en esos niveles por esos "profesionales", a quienes pagamos con nuestros impuestos para eso. Pero luego viene gente como Dostoievski, como Tarkovski, o en este caso Eurípides, y nos explican con minuciosos y refinadísimos análisis que la crueldad es una metástasis del amor, que si la justicia es una recta el sacrificio es una parábola (en sentido geométrico, no literario), o cosas así, y entonces, cuando gracias a esos tratamientos artísticos sentimos más que nunca el vértigo de lo inconcebible, dejamos de leer los periódicos y de consultar a los "profesionales", y pasamos a preguntarles a los dioses, como hacen los coros en las trage- 
dias griegas (en el caso de Medea, encomendándose a sus inescrutables designios).

Las preguntas que elevamos a los dioses son preguntas retóricas, no porque ya nos sepamos las respuestas, sino porque sabemos a ciencia cierta que nadie nos las va a responder jamás. Pero formular esas preguntas desesperadas (en el sentido de que no esperan ser contestadas: "lo inaguardado" es el término que Eurípides emplea en el párrafo final de su tragedia para definir nuestra relación con los dioses) es la manera que nosotros los hombres tenemos para ponernos a la altura del inconcebible absurdo del ser, cara a cara y de igual a igual, desafiando al vértigo con nuestra compostura. La medida infinita de lo inconcebible es la medida infinita de nuestro espíritu. Somos tan infinitos como nuestra miseria. Esa retórica es el arte.

AR: Muchas gracias Alberto por tu tiempo y por compartir este rato con todos nosotros. Ha sido un placer, como siempre, hablar contigo. Naturalmente la conversación podría seguir, pero como en cualquier diálogo filosófico que se precie (como en aquellos platónicos con los que emergía del barro la filosofía) es mejor que éste no advenga sino bajo la forma interrupción. Seguramente una de las fórmulas más filosóficas en español para decir adiós sea ese breve "seguimos hablando" a la que recurro ahora para emplazar este diálogo.

ALBERTO CiRIA es filósofo, y el ganador del premio anual 2015 a la promoción de la Filosofía y la Cultura en Málaga, y ALEJANDRO ROJAS es también filósofo, y el presidente de FICUM, la asociación cultural que organiza y entrega el premio.

\section{Lineas de investigación:}

Filosofía y literatura, idealismo alemán, Heidegger.

Publicaciones recientes:

- Ciria, A., "La luz como yugo, la verdad como no ocultamiento y el alma como aspiración. Un comentario a: Martin Heidegger, De la esencia de la verdad", Thémata 50 (2014), 215-228.

- Rojas, A., “El bien y la intelección según Platón”, Thémata, 50 (2014), 37-68.

Dirección electrónica: alejandro@filosofiaenmalaga.net 